\title{
VIGENCIA DEL PENSAMIENTO DE MAX WEBER
}

Por Juan Opazo M.

\begin{abstract}
"El destino de una época de cultura que ha comido del árbol de la ciencia consiste en tener que saber que podemos hallar el sentido del acaecer del mundo, no a partir del resultado de una investigación, por acabada que sea, sino siendo capaces de crearlo; que las cosmovisiones jamás serán producto de un avance en el saber empírico, y que, por lo tanto, los ideales supremos que nos mueven con la máxima fuerza, se abren camino, en todas las épocas, sólo en la lucha con otros ideales, los cuales son tan sagrados para otras personas como para nosotros los nuestros".

Max Weber, La objetividad cognoscitiva de la ciencia social y de la politica social, 1904.
\end{abstract}

\section{INTRODUCCIÓN}

Discutir acerca de Max Weber, en cualquiera de sus múltiples facetas, constituye un desafío nada despreciable.

Weber representa para la sociología, como para la ciencia social en general, uno de los más grandes hitos; en efecto, Richard Bendix nos habla asi de sus vastas incursiones: "Estudió derecho y economía política; se especializó en la interpretación de doctrinas religiosas y fue un investigador bíblico eminente; alcanzó un cabal dominio técnico en tan varios asuntos como los antiguos métodos romanos de agricultura, las asociaciones mercantiles de la Edad Media y la moderna bolsa de valores; llegó a ser especialista en la historia comparada de las instituciones urbanas; indagó a fondo los problemas del trabajo agrario en las heredades de Alemania oriental; elaboró un plan sistemático para interpretar la antigua civilización mediterránea y la evolución política de Occidente; dedicó un estudio especializado a los orígenes medievales de la música occidental; investigó la productividad de una planta textil de Alemania occidental, e hizo un análisis minucioso de sus condiciones sociales y psicológicas. Contó para todo esto con las ventajas de la cultura clásica alemana; discurría con holgura en siete u ocho idiomas y a ellos añadió el ruso con ocasión de la revolución rusa de 1905; desde el principio hasta el fin de su carrera estuvo tan enfrascado en las controversias metodológicas de las 
ciencias sociales como en las controversias politicas de su país y de su tiempo" (1) (lo destacado es mío).

Sus aportes, en materia de metodología, constituyeron puntos de vista sumamente coherentes, no sólo para su concepción de ciencia, sino para la labor investigativa misma.

El fondo de las reflexiones epistemológicas de Weber fue el estatuto de las ciencias humanas a finales del siglo pasado en Alemania, polémica suscitada en torno a la relación que debería tener una ciencia humana respecto de la ciencia natural; dicho debate fue encabezado por Rickert, Dilthey $y$ Windelband, entre otros, y contó con la activa participación de Weber, que derivará hacia una propues ta personal en torno a la posición de las ciencias "ideográficas" respecto del estatuto de las ciencias en general.

El desarrollo de este ensayo comenzará por exponer las relaciones que se pueden establecer en torno a los conceptos metodológicos fundamentales en Weber, cuestión que nos remite a hilar el marco analítico que le da sustento a su sociología comprensiva. En segundo y último término me abocaré a contrastar las categorías weberianas expuestas, con las dos tesis, que de alguna manera orientan este trabajo, como también motivaron su desarrollo.

\section{DEFINICIÓN DE SOCIOLOGÍA EN WEBER}

Quizás una de las características más distintivas de Weber y su quehacer sociológico fue la pureza conceptual con que ocupaba los elementos que le permitían, de alguna forma, capturar la realidad para entenderla. Su obra "Economía y Sociedad" está abocada, en gran parte, a definir lo que él entendía cuando estaba hablando de un hecho social: pongamos por ejemplo qué es lo que Weber entiende por clase: "Clase es un grupo humano en situación de clase... situación de clase es el conjunto de probabilidades típicas de: provisión de bienes, posición externa y de destino personal; que derivan, dentro de un determinado orden económico, de la magnitud y naturaleza del poder de disposición (o carencia de él) sobre bienes y servicios y de las maneras de su aplicabilidad para la obtención de rentas o ingresos" (2), he allí un claro ejemplo de su capacidad de abstracción y de su conceptualización, cualesquiera fueran las críticas que a nivel teórico pudiesen hacérsele.

Pero queda ver cuál es el fundamento de tanto esfuerzo conceptualizador, en ese sentido nos señala adecuadamente un discípulo: "El punto de partida de él (Weber) es la infinidad intensiva y extensiva de la realidad empírica, conocimiento y acción no se realizan nunca de manera definitiva, ya que el entendimiento no puede introducir o copiar lo real, sino solamente elaborarlo mediante el juego de los conceptos. Entre lo real y el concepto la distancia sigue siendo infinita" (3). Weber es contrario a toda filosofía emanantista, en esa perspectiva Mommsen 
señala respecto de él que: "desde un punto de vista metodológico, el concepto de objetividad del proceso histórico de Marx era una ficción" (4).

Es dentro de este ámbito que debe entenderse la definición que Weber tiene de sociología como asimismo, de un modo circular, deriva cuál es la tarea de esta disciplina. Sociología es para Weber "una ciencia que pretende entender, interpretándola, la acción social para de esa manera explicarla causalmente en su desarrollo y efectos" (5), pero dentro del vasto significado del término acción, Weber acota: "por acción debe entenderse una conducta humana (bien consista en un hacer interno o externo, ya en un omitir o permitir) siempre que el sujeto o los sujetos de la acción enlacen a ella un sentido subjetivo", Weber diferencia, entonces, cuáles son los elementos en que la sociología (en su entendido) debe fijar su atención: "La acción social, por tanto, es una acción en donde el sentido mentado por los sujetos o el sujeto, está referido a la conducta de otros, orientándose por ésta en su desarrollo" (6). Este es sólo el punto de partida para la emergencia de la sociología que pretende interpretar la acción social. Sigamos a Weber en el desarrollo conceptual de los elementos implicados en su concepción de sociología y la tarea de ésta, es decir, los modos en que procede distinguiendo analíticamente los fenómenos derivados y derivables de la acción social con sentido.

\section{PRINCIPALES CATEGORÍAS DE LA SOCIOLOGIA COMPRENSIVA}

La acción social se nos aparece factible de comprensión (ya analizaremos este término tan central en la obra de Weber) mediante el SENTIDO, pero éste no es algo objetivamente correcto, sino algo que nos es accesible por dos vías:

a) Ya sea deseado por un agente individual o por una pluralidad de ellos en un contexto histórico, o bien;

b) Sentidos atribuidos al agente o agentes como tipos construidos; se hace mención al principal modo de comprensión sociológica para Weber que es el tipo ideal. Según Weber se obtiene un tipo ideal "al acentuar unilateralmente uno o varios puntos de vista y encadenar una multitud de fenómenos aislados, difusos y discretos, que se encuentran en gran o pequeño número y que se ordenan según los precedentes puntos de vista elegidos unilateralmente para formar un cuadro de pensamiento homogéneo" (7). El tipo ideal adquiere en Weber una dimensión de gran relevancia, pues más que un modo de acceder a la comprensión, es una estrategia mental que representa una riqueza metodológica indiscutible. A modo de ejemplo: cuando Weber trata el tema de la dominación distingue (con el consiguiente valor heurístico) tres tipos puros de dominación legítima, donde el fundamento primario de la legitimidad puede ser de carácter racional, tradicional o carismático; el fundamento primario de carácter carismático "descansa en la entrega extracotidiana a la santidad, heroísmo o ejemplaridad de una persona y a las ordenaciones por ella creadas o reveladas" (8). El tipo puro de dominación caris- 
mática no se da nítidamente en la historia de las sociedades y sus formas de gobierno, ni es el objetivo que el tipo ideal aludido exista, sino que representa una serie de ventajas contar con él a la hora de analizar concretamente casos de dominación, a su vez es necesario destacar que Weber siempre mencionó que dichas distinciones analíticas nunca se dan puras y tampoco quieren representar estadios sucesivos del desarrollo, en este caso, de las formas de dominación.

En términos de la tarea de la interpretación, cabe señalar que Weber estaba muy conciente de la distinción entre acción significativa (factible de comprender en su desarrollo) y conducta reactiva, es decir, que no asocia ningún significado subjetivamente deseado. Indudablemente ésta adquiere una dimensión arbitraria, en otras palabras, la distinción cabría en el ámbito de la labor investigativa. Esta problemática en Weber nos remite a la distinción entre COMPRENDER e INTERPRETAR, desde luego implícitamente Weber tiene presente a Jaspers, éste argumenta que "de comprender hablamos en la medida que lo comprendido halla su plena exposición a través de los movimientos expresivos, manifestaciones del lenguaje, actos. De interpretar hablamos cuando sólo sirven algunos puntos de apoyo escasos para traspasar relaciones ya antes comprendidas al caso presente con una cierta probabilidad" (9). Del mismo autor Weber toma la distinción entre formas de comprensión:

a) racional (ej. de lo hablado: lo que se habló)

b) empática (ej. de lo hablado: del que habló).

La problemática doble entre elementos reactivos presentes en una acción social y las dos formas que adquiere la certidumbre en la comprensión pueden ser resueltas con el empleo de construcción de tipos, ya que "podemos investigar y hacer plenamente comprensibles aquellas pautas significativas que son irracionales y afectivas siempre que nos la representemos como desviaciones de un tipo puro de acción, como sería el caso si ésta ocurriera de un modo racional deliberado" (10).

La acción social no acontece en un vacío, Weber así lo entiende y es por ello que los acontecimientos y objetos en sí, que carecen de sentido (en los términos definidos por él), son considerados por todas las ciencias de la acción como causas o efectos de la acción humana, o bien como que la provoquen o la impidan, Weber no comete el error de soslayar la influencia de estos "objetos", pues es indudable que poseen una significación cultural que de hecho influye (o puede influir) en el curso de una acción.

La comprensión puede ser de dos tipos, por un lado logra ser directa y por otra es comprensión explicativa, esto es: cuando captamos el motivo de la acción, "para una ciencia que se ocupe de los significados de las acciones, explicar es captar el complejo de significados en los que encaja una acción directamente inteligible en virtud de su significado intencional subjetivo" (11). El proceso de comprender liga una particular relación entre observador y actores, esto es: la dinámica del sociólo- 
go que hace ciencia debe ceñirse a explicar la acción social en su curso. En ese entendido y con ocasión de la inauguración del nuevo grupo editorial de la revista "Archiv für sozialwissenschaft und socialpolitik", conformado por Weber en 1904, junto a Sombart y Jaffé, nos señala en términos más amplios que... "la ciencia que queremos promover es una ciencia de realidad. Queremos comprender la realidad de la vida que nos circunda, y en la cual estamos inmersos, en su especificidad; queremos comprender, por un lado, la conexión y significación cultural de sus manifestaciones individuales en su configuración actual y, por otro, las razones por las cuales ha llegado históricamente a ser asi-y-no-de-otro-modo" (12).

La comprensión se refiere al entendimiento interpretativo del sentido o pauta de sentidos en los tres casos siguientes, según Weber:

a) Realmente deseados en un caso particular;

b) Deseado por el agente medio con cierto grado de acercamiento, o bien,

c) Mediante la construcción de tipos ideales científicamente elaborados a partir de un fenómeno frecuente, esto es, denominado por Weber: significado idealtípico. Pero en la medida en que tratamos con fenómenos que, en palabras de Jaspers, remiten a lo cualitativo en sí, Weber avanza constatando que la certidumbre interpretativa es más bien una hipótesis, dado que concretamente existirian tres grandes categorías de problemas, a saber:

a) Los motivos son difíciles de hacer explicitos por la presencia de mecanismos represivos (ello incluso para los mismos actores). Este hecho más el avance en disciplinas como el psicoanálisis, fundamentalmente por Horney, Fromm, etc., ponen en duda el optimismo de Jaspers en el que "las disciplinas comprensivas (él habla más concretamente de psicologíal tienen amplias posibilidades de expansión, pues lleva lo inadvertido a la conciencia" (13).

b) Algunos procesos externos a la acción que parecen ser los mismos, pueden diferir mucho entre sí e incluso pueden tener para el agente significados opuestos, problemática que nos remite a lo expuesto en al.

c) Los seres humanos en la mayoría de sus actividades desempeñan acciones no unívocas, sino que tiene constantemente presente la existencia de conflictos entre motivos.

Pero Weber continúa adelante y propone que "mediante el frágil experimento mental vía el cual eliminamos hipotéticamente los elementos individuales de la cadena de motivos, podemos reconstruir la causa probable de la acción" (14).

Veamos a continuación cómo Weber es capaz de relacionar los elementos constitutivos de una cadena susceptible de representar causalmente, que hace de su sociología comprensiva una propuesta metodológica sumamente interesante $y$, a la vez, coherente. La unidad que nos liga SENTIDO (mentado subjetivo) con la tarea comprensiva, se denomina motivo. Motivo es un complejo de significados que parece conferir al agente, tanto como al observador, razones significativas para comportarse de una cierta manera. Adecuación al nivel significativo quiere decir 
que una pauta de conducta, en la medida en que las relaciones entre los elementos de dicha pauta constituye un conjunto de significados que, en términos de las convenciones corrientes de pensamiento y sentimiento, podría reconocerse como típicos. Una relación causalmente adecuada existe ahí donde hay una probabilidad determinada por leyes empíricas de que una secuencia de sucesos ocurra siempre igual. Pero Weber es cauto respecto a las posibilidades de cooptación de la realidad científicamente hablando, en efecto, menciona: "Dar una explicación causal es establecer una generalización que afirma que un acontecimiento externo o interno observado irá seguido de otro, o sea, simultáneo con él con un grado de probabilidad calculable de algún modo y que en un caso ideal (y muy poco frecuente) puede ser medido cuantitativamente" (15).

A modo de resumen y respecto a las posibilidades de explicación causal, Weber señala que la "interpretación causal correcta de una acción particular es concebir como apropiado el curso externo de esa acción y su motivo, al tiempo que ambos se entienden como correlacionados entre sí de una forma en que su significado se nos aparezca como comprensible" (16). Weber deduce de su esquema que las leyes sociológicas son referidas únicamente a las generalizaciones estadisticas que encajan con la interpretación del significado intencional de la acción social, en términos de tipos inteligibles de acción.

Los procesos y regularidades que no cuentan con la cualidad de hechos sociológicos, no son menos importantes, y desde el punto de vista de Weber, en términos metodológicos, deben ser tomados como condiciones, estímulos, obstáculos o fomentos de la acción. Esta consideración nos introduce a una temática no muy tratada por Weber, quizás por sus consideraciones filosóficas y concepción de realidad; específicamente me refiero al establecimiento de los límites en torno a un problema de estudio sociológico. Si bien Weber adscribe una posición nominalista, su postura dista muchísimo del ahistoricismo, es decir, en Weber, aun cuando no exista una concepción de totalidad como es entendida en los autores de orientación marxista, no se vislumbra un tratamiento sincrónico extremo, por el contrario, Weber representa un muy buen ejemplo de integración sociológica: capacidad analítica y conocimiento histórico (ver por ejemplo su: "Ética protestante y el espíritu del capitalismo", como sus diversos estudios sobre la religión). Un caso gráfico de la sociología en que se ha mal entendido a Weber lo representa la escuela norteamericana encabezada por Warner, específicamente respecto de los estudios sobre estratificación social; en ese sentido nos señala un entendido del estudio de la estratificación social... "algunas ideas fundamentales de Weber han experimentado una extraña metamorfosis al ser incorporadas a la teoría norteamericana de la estratificación. En el Weber que surge de esta teoría apenas se reconoce al autor de 'Economía y sociedad', desfiguración debida principalmente a que se lo invoca como principal portaestandarte del movimiento contra el materialismo o determinismo económico o contra la interpretación monocausal de la clase social, o 
cualquier término equivalente de lo que pasaba por marxismo durante ese período. Es un Weber que ha sido minuciosamente desmarxificado y a quien, de ese modo, se lo ha acondicionado para asumir tareas de paladín ideológico de la sociedad sin clases del capitalismo norteamericano. Por eso uno busca en vano, en estas diversas propuestas, algún rastro del persistente interés weberiano en la propiedad, la burocracia estatal, los antagonismos de clase o el cambio estructural; o la mención siquiera de que Weber nunca consideró a las dimensiones de la estratificación como agregados de atributos individuales, sino como fenómenos de la distribución del poder en la sociedad" (17). Este ejemplo tiene como objetivo destacar que Weber tuvo siempre presente las limitantes de una ciencia social como la sociología, pero que en ningún caso debíase descuidar el estudio de la historia en pos de un método sincrónico sin empiria que sustentase sus hallazgos.

El término acción en Weber es aplicable en forma adecuada al comportamiento de una o varias personas individuales, para otros efectos, señala Weber, es factible representarse al individuo como un conjunto de, por ejemplo, células. De igual forma, en otras esferas es necesario destacar al individuo en ámbitos colectivos; ejemplos: sistemas, empresas, Estado, etc. Pero Weber es consciente de la importancia de los conceptos colectivos para su sociologia, de hecho nos señala que "la sociología no puede ignorar los conceptos colectivos de otras disciplinas. Ello es así, porque la interpretación de la acción debe referirse a ellos de tres modos:

a) Pues, a veces ellos significan un resultado especificamente estructurado de acciones sociales de individuos plasmados como reales o concebidas como posibles.

b) La representación que se pueda tener de dichos conceptos, es factible de poseer fuerza normativa sobre los individuos.

c) El enfoque funcional sirve a la sociologia interpretativa en dos propósitos: puede servir para la ilustración práctica y la orientación provisional, como también, en algunos casos, ser el único enfoque que nos permite descubrir qué acción social es importante interpretar y comprender, si lo que deseamos es explicar un sistema especifico" (18).

Dado que Weber es explícito en exponer sus planteamientos en torno a la tradicional polémica de la sociología en referencia al objeto de estudio y sus peculiaridades, es decir, lo distintivamente sociológico, cabe entrar en polémica con su postura tildándola de psicologista. Ello deviene de una precaria lectura de los fundamentos metodológicos de Weber, recordemos que el objeto de estudio de su sociología comprensiva son las acciones sociales que asocian un sentido subjetivo por parte de los actores, pero que ocurre orientada por la conducta de otros; recordemos a modo de ejemplo que es justamente esta problemática la que da origen, en Parsons, al problema de la doble contingencia, salvada por la existencia de un sistema normativo que enmarca y determina. 
Luego, es importante tener presente la aclaración de Weber respecto de los resultados que se obtengan de acuerdo a lo anteriormente esbozado, y llama la atención respecto a que "estos resultados, producto de la interpretación, tienen rasgos de carácter hipotético y fragmentario. No obstante, esto es precisamente lo distintivo del modo de aprehensión sociológico de la realidad" (19).

Respecto a la posibilidad de establecer teorías sociológicas de orden comprensivo, tal como él entiende este término, Weber es bastante claro, mencionando que "éstas son proposiciones verificadas por la observación sobre la probabilidad con que se puede esperar cierto resultado de la acción social si se dan ciertas condiciones, las cuales son comprensibles según los motivos típicos y los significados intencionales típicos del agente en cuestión. Son más inteligibles cuando el resultado típicamente observado resulta de la persecución puramente racional de un objetivo y cuando la relación de medios y fines en el contexto es empíricamente claro, vale decir, cuando los medios son inevitables" (20). Es interesante destacar que dicha concepción de lo que Weber entiende por teorías sociológicas, planteado siempre en términos de probabilidad, haya proporcionado marcos analíticos tan fecundos en el desarrollo de la sociología posterior a su muerte, hace ya setenta años. Podemos afirmar con Freund que uno de los aspectos "que más sorprende en Weber es la ausencia de toda doctrina preconcebida.

Si lo dicho hasta aqui nos refiere al papel de la sociología, en cuanto disciplina científica, abocada a la captación de sentidos en las acciones humanas concretas históricamente determinadas, ¿cuál es la diferencia entre la tarea del historiador y la del sociólogo?, Weber nos delimita estos ámbitos consciente de sus interdependencias. Para Weber el historiador intenta suministrar análisis causales y evaluaciones de acciones individuales, sistemas sociales y personas culturalmente relevantes; dicha disciplina estaría en el ámbito de las que ocupan una metodología "individualizante", es decir, que se centra en los caracteres cualitativos y singulares de los fenómenos. La sociología tiende a la precisión conceptual, está en el espacio de las disciplinas que deben lograr planteamientos de un nivel de abstracción mayor, "para que los conceptos tengan un sentido claro, el sociólogo debe formular, por su parte, tipos puros ideales de sistemas relevantes que muestren la coherencia interna y la unidad que pertenece a la mayor adecuación posible al nivel de significado" ...y una vez más nos vuelve a poner sobre aviso respecto de las limitantes de una empresa científica social, según sus términos, "en la vida real, la acción significativa y genuinamente efectiva (es decir, plenamente consciente y claramente comprensible) es sólo un caso límite, en la mayoría de los casos en el mundo real los agentes actúan en un estado de autoconciencia confusa o inconsciencia total de su significado intencional" (21). Sobre estas consideraciones volveré más tarde, cuando se infiera un postulado ontológico que guía de alguna manera sus concepciones metodológicas, pero no por ello le restan validez.

Desarrollemos a continuación el concepto de acción social en Weber, para 
derivar a su tratamiento metodológico y las diversas instancias de análisis distinguidas por él en torno a la unidad básica de su sociología comprensiva. En primer término, la acción social se encuentra relacionada con el pasado, el presente o con la conducta futura anticipada de otras personas; la conducta se hace social cuando es tomada en consideración la conducta de terceros. Más específicamente: el contacto humano es social cuando la conducta de una persona se relaciona en su significado refiriéndose al comportamiento de los demás. De ese modo, una acción cuyo carácter se determine en todo o en parte de modo puramente reactivo por la mera existencia de una multitud, no constituye una acción social. Caracteriza de forma muy clara este tipo de conductas, Le Bon; nos menciona agudamente: "Desvanecimiento de la personalidad consciente, predominio de la personalidad inconsciente, orientación por vía de sugestión y contagio de los sentimientos y las ideas en un mismo sentido, tendencia a transformar en actos las ideas sugeridas; tales son, pues, las características del individuo en muchedumbre. No es un individuo, es un autómata en quien no rige la voluntad... El individuo en muchedumbre es un grano de arena colocado junto a otros granos de arena también, a quienes el viento mueve a su capricho" (22).

Weber diferencia analíticamente cuatro tipos de acción social, he aqui una excelente aplicación de su método idealtípico. Las acciones sociales distinguidas son:

a) Acción social racional de acuerdo a fines: caracterizada por el uso de medios apropiados (determinados de forma analítica) para el logro de un fin especificado.

b) Acción social racional de acuerdo a valores: donde la conducta de un sujeto o sujetos tiende a la realización de un valor trascendente.

c) Acción social afectiva o emocionalmente determinada: caracterizada primordialmente por los impulsos emocionales y estados de ánimo.

d) Acción social tradicional: conducta que es expresiva de la costumbre establecida.

Tenemos que "los tipos mencionados son más bien abstracciones puras concebidas con propósitos sociológicos, a los cuales puede aproximarse la acción real en menor o mayor grado o mediante los cuales puede componerse lo que es más frecuente" (23).

Dado que la acción social se orienta en su desarrollo teniendo presentes a los demás, existe en él una noción de interacción acorde con su esquema general, dicha conexión Weber la denomina relación social, y ésta existe "cuando varias personas ajustan recíprocamente su conducta entre sí con respecto al significado que le atribuyen, y cuando ese ajuste reciproco determina la forma que ella toma" (24). La relación social puede ser de diversa índole, lo central es que exista una relación mínima entre la acción de cada persona y la de los demás; la reciprocidad es entendida como que el sentido de que aquellos que relacionan sus acciones entre si en un caso dado, confieran el mismo significado a su relación social, o que 
el significado que cada cual confiera en su fuero interno a su propia acción, varíe en correspondencia con el de los demás.

\section{EN TORNO A LAS CATEGORIAS METODOLÓGICAS EN WEBER}

En la primera sección se hace una revisión de las principales categorías metodológico-sociológicas de Max Weber, dicha tarea fue realizada con un afán más bien explicativo, corresponde ahora desarrollar las dos tesis que orientaron este trabajo. Dichas tesis en ningún caso pretenden erigirse como "lecturas" originales de los planteamientos metodológicos weberianos, por el contrario, han sido bastante tratadas (aun en términos implícitos) por una multiplicidad de autores; el objetivo es intentar mostrar su desarrollo coherente, con miras a ampliar el acceso a este sociólogo que tanto aporte ha hecho a la ciencia social.

El primer planteamiento que desarrollaré será la revisión de algunos elementos de Weber, que nos denoten cómo sus aportes en materia de metodología devienen de una particular concepción de la realidad, sustentados en su posición filosófica y política.

Recordemos que para Weber no existiría un en sí en la vida social factible de pesquisar por el científico social, adhiere a una posición nominalista en sociología; recordemos la cita que inicia este ensayo: "...podemos hallar el sentido del acaecer del mundo, no a partir del resultado de una investigación, por acabada que sea, sino siendo capaces de crearlo...". En su lógica la realidad es asible mediante la adecuación continua de los conceptos, pero que, como nos señalara Freund respecto de su postura, "entre lo real y el concepto la distancia sigue siendo infinita". Para Weber la vida y el mundo son fundamentalmente irracionales, dicha irracionalidad es originada por:

a) La vida afectiva;

b) Las relaciones con el poder;

c) El azar y la imprevisibilidad, y

d) En la irracionalidad ética del mundo; derivada de los elementos insuperables, según él: el antagonismo de los valores y la paradoja de las consecuencias, es decir, que nos es imposible prever el resultado de una acción en toda y cada una de sus instancias.

En el ensayo de Weber titulado "La política como vocación" (conferencia dictada en el año 1918), nos invita a reflexionar acerca de la acción política; su solución, no siendo una propuesta científica en sus términos, nos muestra cómo concibe Weber que debemos conducirnos para "tener derecho a poner la mano en la rueda de la historia" (25), es decir, para tomar decisiones en el campo de lo político. Su solución apunta a que el político debe incorporar a su quehacer dos máximas éticas que le permitan conducirse adecuadamente, en vistas a cuidarse 
de la irracionalidad del mundo: la ética de la responsabilidad, que dice relación con la capacidad de evaluación que debe tener un político, cuando toma alguna decisión que tenga como objetivo influir en el desarrollo de los acontecimientos de la vida social, dado el supuesto de la paradoja de las consecuencias. La otra es la ética de la convicción, que alimentaría de pasión la actividad propiamente política. Con indudable fineza nos plantea Freund que en un sentido la concepción weberiana de la ciencia está dominada por la de la política; a la multiplicidad de los valores y de los fines, corresponden la multiplicidad y el antagonismo de los puntos de vista por los cuales un fenómeno puede explicarse científicamente (26).

En su tiempo polemizó, ya sea implícita o explícitamente, con los conceptos teórico-metodológicos ocupados por los socialistas en Alemania. Su crítica se centró en las profecías contenidas en el "Manifiesto" y esgrimidas por los socialdemócratas de su época respecto a la tendencia del desarrollo capitalista, el esencialismo propugnado por la concepción marxista del devenir de la historia, era para Weber absolutamente errado, por cierto sin descartar las hipótesis derivables de los textos marxistas. Para Weber el marxismo era aceptable sólo en una forma doble: "o bien como una teoría politica que, en lugar de invocar para sí verdades científicas objetivas, proclamaba, sobre la base de convicciones éticas fundamentales, la lucha revolucionaria en contra de un orden socialmente injusto, sin tener en cuenta para nada las consecuencias que ello pudiera tener para el individuo; o bien como una brillante sistematización de hipótesis idealtípicas que, en tanto tales, merecen la mayor atención de todos los científicos sociales y que logran promover esencialmente nuestro conocimiento acerca de las características de las sociedades modernas" (27). Pero al contrario de muchos sociólogos que polemizaron con el marxismo como doctrina con pretensiones de ciencia, Weber no descartó jamás la determinante influencia de los aspectos económicos en el acaecer de la vida social... fue más allá, abocándose a buscar otro tipo de elementos sustancialmente determinantes, con el objeto de complementar los análisis de origen marxista.

Uno de los elementos siempre presentes en los análisis weberianos, aunque en la mayor parte de ellos, adecuadamente filtrado, es el principio de la racionalidad, éste denotaba una época en que la clara tendencia en el mundo social apuntaba a un proceso de formación creciente de relaciones puramente racional-funcionales; todo esto en el advenimiento de rígidas estructuras burocráticas (empresa con cálculo racional de la ganancia y en donde el obrero era separado de los medios de producción, ejército moderno, sistema escolar, etc.). Ese era para Weber quizás el problema filosófico más importante, una tendencia histórica inevitable. Al contrario de la desalienación planteada por el marxismo cuando luego de una fase de transición advenga el comunismo con la consiguiente abolición del Estado y la eliminación de todas las desigualdades sociales, Weber permaneció siempre pesimista, y pronosticó que cualesquiera fueran las formas de organización política de 
un país, las instancias de dominación contenidas en las estructuras burocráticoformalizadas no serían abolidas nunca... ¿no parece un acierto teórico de suma trascendencia respecto a la actual situación en Europa? En el plano político institucional Weber estuvo siempre abogando por la presencia de líderes carismáticos, que de algún modo contrapesarían las tendencias burocráticas (concreciones de la racionalización), que detendrían, por algunos períodos, el "desencanto" producido por dicha tendencia. Con acierto nos señala Mommsen que "la democracia plebiscitaria del líder o lo que objetivamente conduce a lo mismo, las formas cesaristas de la conducción de masas, le parecian a Weber indispensables para el moderno funcionamiento de la democracia de masas. Pues sólo las grandes personalidades de conductores, dotadas de la capacidad de ganar a las masas para sí y para sus objetivos personales, gracias a sus cualidades demagógicas positivas, podían, en su opinión, contrarrestar con éxito el peso burocrático de los partidos políticos e indicarles sus metas y su dirección" (28), agregando que "son los individuos, y en verdad los grandes individuos quienes en virtud de su capacidad para profesar valores y declararlos obligatorios para sí y para los demás, pueden imponer metas al acontecer social" (29).

En varias formas puede establecerse un nexo entre las categorías metodológicas en Weber con su "weltstauchaung" global, lo importante es que tras un cuadro de aparente objetividad (ya veremos a continuación cómo Weber es capaz de saltar esta problemática), se esconde una concepción de la realidad y del mundo, que determina los modos, tanto como las formas del conocer... no sólo es consciente de ello, sino posee, de igual forma, una propuesta al respecto. El problema de la objetividad cognoscitiva en Weber se esclarece precisamente porque el autor ataca de lleno la principal fuente de obstáculos en la investigación científica y las pretensiones que ésta tenga en términos de objetividad. Weber distingue dos instancias axiológicas:

a) Juicios de valor, que vendrían dados por una evaluación personal acerca de lo bueno, lo malo, lo justo o injusto, etc., de un hecho social. En ciencia esto se manifiesta en la propuesta de un "deber ser", pero esto corresponde al terreno de la filosofía y no a la ciencia social.

b) Referencia a valores, indudablemente la labor científica no está jamás desempeñada en un vacío cultural, por el contrario, se encuentra inmersa en un tiempo determinado que a su vez establece (en forma figurada) los límites para la praxis científica. Como dicha labor se lleva a cabo en un contexto social plagado de valores en pugna, la ciencia, y más específicamente el científico que investiga, debe, necesariamente, referirse a ellos de una forma que no perjudique las pretensiones de objetividad de la investigación. Veamos en primer lugar en qué forma la relación del científico con los valores influye en su labor:

a) Indudablemente la elección de un área de estudio es determinada por los intereses valorativos del científico. 
b) La selección del material de estudio también es sesgada en favor de valores, ya que en la mayoria de los casos el científico adhiere a una postura teórica específica.

c) Los límites también son determinados por la acción de los valores, ya que ellos establecen la indicación de las relaciones de causalidad a establecerse y hasta donde es factible extender la regresión.

Pero lo anterior no elimina la posibilidad de ser objetivos, y ella radica, según Weber, en la posibilidad de establecer un conocimiento que posea validez intersubjetiva, más allá de que existan valores en conflicto entre investigadores de diferentes corrientes teóricas. En otros términos, la objetividad de una investigación está dada por la rigurosidad metodológica puesta en ella. "En cuanto al cómo, al método de investigación, el punto de vista es determinante para la construcción del esquema conceptual que se empleará en la investigación. En el modo de su uso, sin embargo, el investigador está evidentemente ligado, en éste como en todos los casos, por las normas de nuestro pensamiento. Pues la verdad científica es lo que pretende valer para todos aquellos que quieren la verdad" (30).

Así he tratado de establecer, como primera tesis, algunas de las relaciones más destacables entre el "Weber" metodólogo y otras facetas de su prolifico quehacer. A continuación se analizarán estos elementos a la luz de circunstancias más concretas, destacando cómo hoy en día, a mi entender, la propuesta de Weber, en términos teórico-metodológico, adquiere una vigencia inusitada.

Todo parece indicar que la historia contemporánea tiende a escaparse de los esquemas teóricos totalizantes que tanto fuero tuvieron hasta mediados de este siglo, al menos en lo referente a la sociología. Cada vez con más fuerza las doctrinas que originaron marcos analíticos en lo social tienden también a relativizarse y a aceptar esquemas teóricos paralelos sin la antigua y consabida descalificación por "vía de lo ideológico", incluso en las tan anunciadas crisis de la sociología (Gouldner por ejemplo) se deja sentir un aire que impele a la renovación... ¿Qué son sino los vientos postmodernistas que surgen en Europa y que se manifiestan de manera palpable en la elaboración de teorías sociológicas sumamente contingentes? ¡Dicho razonamiento ataca de manera central el problema de la sociología en cuanto a establecerse con el rótulo de ciencia! Weber no quedó enfrascado en esta polémica que, por cierto, no es de ayer, sino avanzó en un difícil momento para la sociología en cuanto disciplina con pretensiones de constituirse en ciencia.

Los recientes acontecimientos en Europa y América auguran un profundo cambio en todos los ámbitos, y de forma más importante aún en los paradigmas de la explicación sociológica... pero debemos esperar al menos una década.

El paso de recientes regímenes militares hacia sistemas democráticos denota un renacer que debemos entender a la luz de las crisis de las concepciones superideologizadas; hay una valoración de la democracia como valor en sí, al menos por la mayoría de los sectores políticos de la región. Hay lecciones para todos: ni "el" 
modelo cubano, ni "las" políticas neoliberales de corte ortodoxo son la panacea para la superación de los problemas concretos que existen en nuestros países.

Un intelectual de renombre, Humberto Maturana, tiende a elevar, en términos teóricos, postulados como "la aceptación del otro como legítimo otro en la convivencia", a propuestas ontológicas. Pero la presentación de estos elementos en cierta forma caótica significan que las proposiciones metodológicas de Weber vuelven a ponerse en el tapete como alcances científicos de innegable aporte a la sociología.

Lo más trascendente a mi entender es que los elementos propuestos por Weber carecen de la rigidez que, lamentablemente, han afectado a otros. Ello permite ocupar sus categorías de origen, tanto metodológico como teórico, con resultados fecundos para la sociología en la comprensión de los fenómenos sociales.

Si miramos una de las revistas de sociología más prestigiosas del mundo, el British Journal of Sociology, de marzo de 1989, aparece un artículo que polemiza con la interpretación que hacen otros autores respecto de la utilidad de las categorías comprensivas para estudiar la estratificación, más específicamente los grupos de status.

A modo de conclusión, es conveniente delimitar la importancia que tiene para la sociología la profundización de las dos tesis que se han intentado desarrollar aquí:

a) El desprejuiciarse teóricamente ha resultado mucho más prolífico en términos teóricos, que el freno en discusiones anacrónicas respecto a, por ejemplo "la verdad", en lo que a sociología y el desarrollo de ésta se refiere.

b) La inquietud weberiana por todo tipo de interpretaciones, su innegable espíritu crítico frente a las explicaciones ideologizadas, tanto como su apego al estudio de la historia y sus aportes teórico-metodológicos representan, para la sociologia, algo que sigue siendo contemporáneo, a pesar de ser un "clásico".

La modalidad que considero más susceptible de crítica respecto a los postulados de Weber es la exigencia a la cual pudiesen someterse sus categorías en términos analíticos. Pero ello rebasa infinitamente las pretensiones de este ensayo, queda de manifiesto, al menos, mi postura frente a sus aportes... como menciona un conocido autor: "las teorias están allí para ser interrogadas y exigidas", y en la medida en que ello ocurra, la ciencia se encarga, sabiamente, de desecharlas, reformularlas, etc. Parece, en vista a lo expuesto, y teniendo en cuenta las limitaciones del "espíritu del tiempo", que las propuestas de Max Weber no pertenecen a las primeras.

Es necesario promover el acercamiento siempre crítico a Max Weber, en razón de la reelaboración más adecuada de algunas de sus categorias para provecho de la explicación sociológica y su devenir: como síntesis reconocemos con Mommsen 
que, "según Weber, no existe ninguna ley 'objetiva' de la realidad. En el mejor de los casos, con la ayuda de tipos ideales es posible construir teorías de los procesos sociales, que tienen alguna semejanza con leyes y que pueden servir como pautas para medir el grado de apartamiento de determinados sectores de la realidad social con respecto a estos modelos nomológicos" (31).

\section{CITAS BIBLIOGRÁFICAS}

Notas: para una mayor fluidez en las citas se ha dispuesto hacer referencia al libro de donde fueron extraídas con el número al que corresponde en la presentación de la bibliografía:

1. Bendix, R. (texto 10), cap. 15, p. 437.

2. Weber, M. (texto 6), parte IV, p. 242.

3. Freund, J. (texto 9), cap. 1, p. 15.

4. Mommsen, W. (texto 8), p. 172.

5. Weber, M. (texto 4), sección a).), p. 8.

6. WeBER, M. (texto 4, sección a).), p. 8.

7. Weber, M. (texto 5 , sección a).), p. 47.

8. Weber, M. (texto 6), p. 172.

9. Jaspers, K. (texto 2), p. 358.

10. WebER, M. (texto 4, sección a).), p. 14.

11. WeBER, M. (texto 4, sección a).), p. 18.

12. Weber, M. (texto 5, sección a).), p. 61.

13. Jaspers, K. (texto 2), p. 353.

14. Weber, M. (texto 4, sección a).), p. 21.

15. Weber, M. (texto 4, sección a).), p. 23.

16. Weber, M. (texto 4, sección a).), p. 23.
17. PARKIN, F. (texto 3), p. 687.

18. WeBER, M. (texto 4, sección a).), pp. 26-27.

19. Weber, M. (texto 4, sección a).), p. 28.

20. Weber, M. (texto 4, sección a).), p. 33.

21. Weber, M. (texto 4, sección a).), p. 37.

22. Le Bon, G. (texto 1), pp. 25-26.

23. Weber, M. (texto 4, sección a).), p. 45.

24. Weber, M. (texto 4, sección a).), p. 47.

25. Weber, M. (texto 7), p. 349.

26. Freund, J. (texto 9),

27. Mommsen, W. (texto 8), p. 175.

28. Mommsen, W. (texto 8), p. 59.

29. Mommsen, W. (texto 8), p. 126.

30. Weber, M. (texto 5, sección a).), p. 73.

31. Mommsen, W. (texto 8), p. 173.

\section{BIBLIOGRAFÍA}

1. Le Bon, Gustav, Psicologia de las multitudes, introducción, ed. mexicana, 1956 (sin año de edición).

2. Jaspers, Karl, Psicopatología general, traducción de la quinta ed. en alemán por el Dr. R. Saubidet, ed. Bini, B. Aires, 1955.

3. Parkin, Frank, Estratificación social, en Bottomore y Nisbet: "Historia del análisis sociológico", ed. Amorrortu, 1988 (primera ed. en inglés 1978).
4. Weber, MAX, La acción social: ensayos metodológicos, ed. Península, 1984, traducción del alemán de M. Faber Kaiser y Salvador Giner (contiene: a) cap. 1 de Wirschaft und Gese//schaft, Tubinga, J.C. Mohr cuarta ed. 1956, vol. 1, pp. 1-14 (primera ed. 1922). b) Weber: Gesammelte aufsatze sur Wis. senschafts/ehre, Tubinga, J.C. Mohr, ed. de 1919).

5. WebER, Max, Ensayos sobre metodologia 
sociológica, ed. Amorrortu, segunda reimpresión al castellano 1982 (primera ed. 1973) (contiene: a) La objetividad cognoscitiva de la ciencia social y la política social, 1904.

b) Estudios críticos sobre las ciencias de la cultura, 1906. c) Sobre algunas categorias de la sociología comprensiva, 1913. d) El sentido de la neutralidad valorativa de las ciencias sociológicas y económicas 1917).

6. Weber, Max, Economia y sociedad, FCE, primera ed. 1944, segunda ed. 1964, de la cuarta edición alemana de 1956.
7. WeBer, MAX, Escritos politicos, tomo II, primera ed. en español 1982 (del alemán).

8. Mommsen, Wolfang, Max Weber: sociedad, politica e historia, ed. Alfa, 1981 (primera ed. 1974).

9. Freund, Julien, Sociología de Max Weber, ed. Península.

10. Bendix, ReINHARD, Max Weber: Un retrato intelectual, ed. Amorrortu, 1964.

11. Mitzman, Arthur, La jaula de hierro, una interpretación psicohistórica de Max Weber. ed. Alianza, ed. al español de 1966. 